\title{
Influencing the design outcome
}

\author{
Camille Dickson-Deane ${ }^{1}$
}

Published online: 8 February 2021

(c) Association for Educational Communications and Technology 2021

\begin{abstract}
Bennett et al.'s (2017) work on teachers design practices addresses the exact activities that teachers had to complete in order to quickly shift to a digital form of delivery. The pandemic required teachers to modify their pedagogical designs and deliveries to reduce the risk of harm to themselves and those in their care. For many, switching from one mode of delivery (i.e., face to face) to a digital format meant that the appropriate designs had to be sacrificed to meet deadlines. Deadlines which were, in most cases difficult to achieve. The following summarizes eight essays from scholars, researchers and practitioners all providing much needed guidance to support this pivot to the digital space.
\end{abstract}

Keywords Instructor design practices · Novice designer · Instructional designer · Reflection $\cdot$ Humanizing pedagogy $\cdot$ Culturally responsive $\cdot$ Flexible pathways $\cdot$ Nonsystematic designs

Bennett et al.'s (2017) work on teachers design practices addresses the exact activities that teachers had to complete in order to quickly shift to a digital form of delivery. The pandemic required teachers to modify their pedagogical designs and deliveries to reduce the risk of harm to themselves and those in their care. For many, switching from one mode of delivery (i.e., face to face) to a digital format meant that the appropriate designs had to be sacrificed to meet deadlines. Here, defining "appropriate" for a digital format requires knowledge, planning and expertise to produce a pedagogic solution suited to the educational context. Bennett et al.'s (2017) provides a lens of what is "appropriate" through the mapping of experienced teacher's design efforts. These efforts demonstrated iterative, reflective and elaborative activities which were used to produce learnings. The study illustrated a model with detailed paths used to action an instructional design process regardless of discipline for both new and existing curriculum, thus outlining the complexity of the process, the skill required to execute and thoughts needed to act as driver to achieve learning outcomes (Goodyear 2015; Jonassen 2008).

The responses to this study highlight opinions that are grouped into two categories. These responses stayed true to Goodyear's (2015) statement that "design is not a panacea"

Camille Dickson-Deane

camille.dickson-deane@uts.edu.au

1 University of Technology Sydney, Broadway, PO Box 123, Sydney, NSW 2007, Australia 
(p. 28) and that with more planning and capacity to design there will be benefits for all of the stakeholders. The two themes are:

1. Those who design for learning: Here, Kanjanapongpaisal and Antee (2020) discuss the characteristics of the study's population that was not included (i.e., novice teachers) by asking key questions surrounding novice teachers and their design practices. Additionally, Lohman's (2020) response focused on those who typically assist teachers with these design activities. In her response, she discusses how to resource the support for these activities with instructional/learning designers (IDs) with the understanding that different needs require different approaches.

2. The practice of designing for learning: The responses here suggested when pivoting quickly to the digital space, design practices should include the use of systematic models and tools to support teachers in their development processes (Connolly and Hall 2020); have teachers deliberately reflect as part of the design process (Hrastinski 2020), use non-systematic design cycles (Lee 2020), include humanizing pedagogical and/or pedagogy of care (Karakaya 2020), consider culturally responsive designs (Engerman and Otto 2020) and create flexible pathways for teachers to engage in the practice of design (Galyen et al. 2020).

These responses address some of the considerations that teachers in all sectors struggled with, during the pandemic. Additionally, there are gaps in the literature where more support can guide these transitions:

- Measuring intent versus actual design practices (Whitford 2020)

- Contributions of design practices from parts of the world where the current research/ literature is in other languages or rarely found in English publications

- Learning designs that use contextual weakness and turn them into achievable outcomes (e.g., environments with limited ICT infrastructure or weather patterns such as hurricanes or earthquakes)

- Designs that change cognitive constructs (Individual differences literature)

- Policies that can promote more professional development education for the teaching profession

All of these and more can close some of the gaps in the literature which can support these and similar situations, like the pandemic, in the future.

\section{References}

Bennett, S., Agostinho, S., \& Lockyer, L. (2017). The process of designing for learning: Understanding university teachers' design work. Educational Technology Research and Development, 65(1), 125-145. https://doi.org/10.1007/s11423-016-9469-y.

Goodyear, P. (2015). Teaching as design. Herdsa Review of Higher Education, 2, 27-50.

Jonassen, D. H. (2008). Instructional design as design problem solving: An iterative process. Educational Technology, 48(3), 21.

Whitford, T. (2020). We need to provide structure, but with open arms "An exploration of intent and practice of social learning design by teachers", doctoral research presentation at the Melbourne Centre for the Study of Higher Education, April 21, 2020. 


\section{Responses papers in the shifting to digital special issue}

Connolly, C., \& Hall, T. (2020). Designing for emergency remote blended and online education: A response to Bennett et al 2017. Educational Technology Research and Development. https://doi.org/10.1007/ s11423-020-09892-0.

Engerman, J. A., \& Otto, R. F. (2021). The shift to digital: Designing for learning from a culturally relevant interactive media perspective. Educational Technology Research and Development. https://doi. org/10.1007/s11423-020-09889-9.

Galyen, K., Meekins, D., \& Kilgore, W. (2021). Supporting teachers designing in liminality: Embracing a new and flexible way forward. Educational Technology Research and Development. https://doi. org/10.1007/s11423-020-09923-w.

Hrastinski, S. (2020). Informing designs for learning when shifting to digital. Educational Technology Research and Development. https://doi.org/10.1007/s11423-020-09894-y.

Kanjanapongpaisal, P. G., \& Antee, A. (2020). University teachers' design work: Implications for an urgent shift to digital. Educational Technology Research and Development. https://doi.org/10.1007/s1142 3-020-09881-3.

Karakaya, K. (2020). Design considerations in emergency remote teaching during the COVID-19 pandemic: A human-centered approach. Educational Technology Research and Development. https://doi. org/10.1007/s11423-020-09884-0.

Lee, D. (2021). The process of designing for [online] learning: Response to Bennett et al. Educational Technology Research and Development. https://doi.org/10.1007/s11423-020-09915-w.

Lohman, L. (2020). Build, buy, or rent? A systems view of faculty design work in the digital learning era. Educational Technology Research and Development. https://doi.org/10.1007/s11423-020-09899-7.

Publisher's Note Springer Nature remains neutral with regard to jurisdictional claims in published maps and institutional affiliations.

Camille Dickson-Deane PhD, is a Senior Lecturer Higher Education Learning Design at the University of Technology Sydney. She has a MSc in Software Development and Management and a PhD in Information Science and Learning Technologies from the University of Missouri-Columbia, USA. Dr. Dickson-Deane is a Fulbright and Organisation of American States (OAS) scholar who has published journal articles, book chapters and media pieces whilst also producing artefacts, completing expert reviews and conducting evaluations on learning designs. Her research interests include pedagogical usability, individual differences and contextualizing online learning designs. 